\title{
Tracking the aesthetic outcomes of prosthetic breast reconstructions that have complications
}

\author{
Lauren $M$ Mioton $B S^{1}$, Akhil Seth $M D^{2}$, Jessica Gaido $B S M P H^{2}$, Neil A Fine $M D^{2}$, John YS Kim $\mathrm{MD}^{2}$
}

\begin{abstract}
LM Mioton, A Seth, J Gaido, NA Fine, JYS Kim. Tracking the aesthetic outcomes of prosthetic breast reconstructions that have complications. Plast Surg 2014;22(2):70-74.
\end{abstract}

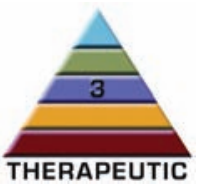

BACKGROUND: Aesthetic results following breast reconstruction have been shown to be a major contributor to patient satisfaction. While many presume that complications after reconstruction impact final aesthetic results, little data exist to substantiate this putative relationship.

OBJECTIVE: To track and evaluate aesthetic outcomes following implant reconstructions with complications.

METHODS: A chart review was conducted on a series of consecutive expander-implant breast reconstructions performed by the senior author between 2004 and 2012. Included patients completed their prosthetic reconstruction or converted to autologous methods and had a minimum follow-up period of 130 days. Four blinded members of the division of plastic surgery independently rated postoperative anterior photographs of patients' breasts using a validated scoring scale with respect to five distinct aesthetic domains: breast mound volume, contour, placement, scarring and inframammary fold.

RESULTS: Of the 172 patients who met the inclusion criteria, 36 experienced a complication. The tissue expander in one-half of these patients was salvaged and the remaining patients converted to autologous reconstruction. The average aesthetic scores for each domain did not differ significantly between patients who experienced a complication and retained their expander and those who did not experience a complication. Patients who converted to autologous tissue reconstruction after experiencing a complication had the highest aesthetic scores.

DISCUSSION: The ability to obtain aesthetic results following a complication that were not statistically different from results in those without complications may reflect the surgeon's refined attempt to salvage the initial implant reconstruction; in other circumstances, the improved cosmesis was achieved through conversion to an autologous tissue-based method. CONCLUSION: The present study quantitatively assessed the impact of complications on aesthetic outcomes following implant breast reconstruction. Continuance of prosthetic reconstruction and conversion to autologous reconstruction serve as viable options to obtain adequate aesthetic scores following a complication. Information gained from the present analysis will help manage patient expectations.

Key Words: Aesthetic; Breast reconstruction; Outcomes; Prosthetic

$\mathrm{R}$ reast reconstruction can help moderate the distressing postoperaB tive changes in body image and the quality of life of breast cancer patients undergoing mastectomy (1-4). In particular, the literature has shown aesthetic results following reconstruction to be a major contributor to patient satisfaction and overall quality of life (5). With numerous reconstruction techniques currently available, myriad studies have detailed the postoperative surgical and cosmetic outcomes of such methods. In addition, factors that may influence final aesthetic results, such as body mass index (BMI), preoperative and postoperative radiation, and age, have also been assessed (6-21). However, little data regarding the impact of postoperative complications on aesthetic

\section{Le suivi des résultats esthétiques des reconstructions par prothèses mammaires qui s'associent à des complications}

HISTORIQUE : Il est démontré que les résultats esthétiques après une reconstruction mammaire contribuent énormément à la satisfaction des patientes. On présume souvent que les complications observées après une reconstruction nuisent aux résultats esthétiques finaux, mais il existe peu de données pour corroborer ce prétendu lien.

OBJECTIF : Suivre et évaluer les résultats esthétiques après des reconstructions par prothèse s'associent à des complications.

MÉTHODOLOGIE : Les chercheurs ont examiné les dossiers consécutifs de reconstructions mammaires par prothèses d'expansion effectuées par l'auteur principal entre 2004 et 2012. Les patientes participantes ont subi une reconstruction prothétique complète ou sont passées à une méthode autologue et ont été suivies pendant au moins 130 jours. Quatre membres de la division de chirurgie plastique ont évalué de manière indépendante et en insu les photographies postopératoires antérieures des seins des patientes au moyen d'une échelle d'évaluation validée dans cinq domaines esthétiques : volume du monticule mammaire, contour, emplacement, cicatrices et pli inframammaire.

RÉSULTATS : Chez les 172 patientes qui respectaient les critères d'inclusion, 36 ont présenté une complication. La moitié d'entre elles ont pu conserver leur prothèse d'expansion, mais les autres sont passées à une reconstruction autologue. Les résultats esthétiques moyens de chaque domaine ne différaient pas de manière significative entre les patientes qui avaient subi une complication et conservé leur prothèse et celles qui n'avaient pas subi de complication. Les patientes qui sont passées à une reconstruction par tissus autologues après une complication obtenaient les meilleurs résultats esthétiques.

EXPOSÉ : Les résultats esthétiques après une complication qui n'étaient pas statistiquement différents de ceux des patientes n'ayant pas vécu de complication reflètent peut-être la tentative perfectionnée du chirurgien de sauvegarder la prothèse initiale. Dans les autres situations, la conversion aux tissus autologues favorisait une meilleure esthétique.

CONCLUSION : La présente étude visait à obtenir une évaluation quantitative des effets des complications sur les résultats esthétiques après une reconstruction mammaire par prothèse. Le maintien de la reconstruction par prothèse et la conversion à une reconstruction autologue permettaient d'obtenir des résultats esthétiques satisfaisants après une complication. L'information tirée de la présente analyse contribuera à gérer les attentes des patients.

${ }^{1}$ Vanderbilt University School of Medicine; ${ }^{2}$ Division of Plastic and Reconstructive Surgery, Northwestern University, Feinberg School of Medicine, Chicago, Illinois, USA

Correspondence: Dr John YS Kim, 675 North St Clair Street, 19-250, Chicago, Illinois 60611, USA. Telephone 312-695-6022,

fax 312-695-5672, e-mail jokim@nmh.org 
TABLE 1

Preoperative patient demographics and characteristics

\begin{tabular}{lccc}
\hline & \multicolumn{2}{c}{ Complication } & \\
\cline { 2 - 3 } Characteristic & No $(\mathbf{n}=\mathbf{1 3 6})$ & Yes $(\mathbf{n}=\mathbf{3 6})$ & $\mathbf{P}$ \\
\hline Age, years, mean \pm SD & $49.31 \pm 15.53$ & $51.57 \pm 8.35$ & 0.547 \\
Body mass index, mean \pm SD & $27.04 \pm 5.91$ & $29.40 \pm 6.06$ & $0.038^{*}$ \\
Diabetes & 2.22 & 11.11 & 0.106 \\
Smoking & 5.88 & 0.00 & 0.597 \\
Hypertension & 19.12 & 16.67 & 1.000 \\
Radiation & & & \\
$\quad$ Previous radiation & 6.06 & 12.50 & 1.000 \\
$\quad$ Postoperative radiation & 18.75 & 29.41 & 0.335 \\
Chemotherapy & 46.21 & 58.82 & 0.327 \\
Acellular dermal matrices & 48.51 & 36.84 & 0.730 \\
Bilateral & 41.91 & 50.00 & 0.515 \\
\hline
\end{tabular}

Data presented as \% unless otherwise indicated. *Statistically significant.

result in poorer cosmetic outcomes in these patients. Previous studies involving reconstruction patients have focused on the overall aesthetics associated with various methods, with some additional analysis of factors that may have contributed significantly to the final cosmetic result $(6,10,13,15)$. Such studies have revealed that autologous tissue-based reconstruction can yield superior aesthetic results compared with prosthetic methods $(6,18,19)$, while implicating breast size, final implant volume, radiation status and BMI as important contributors to aesthetic outcomes in the implant population $(10,11)$.

The present study aimed to track aesthetic outcomes in implant breast reconstruction cases that involved complications. A more thorough understanding of how complications influence aesthetics may be derived from our use of a validated aesthetic scoring scale. Moreover, we stratified aesthetic outcomes according to a more detailed validated metric that encompassed breast mound volume, placement, contour, scarring and inframammary fold definition.

\section{METHODS}

Following institutional review board approval, a retrospective chart review was conducted on a series of consecutive expander-implant breast reconstruction operations performed by the senior author between 2004 and 2012. Patients were excluded from the study if they had $<130$ days of follow-up. Demographic and oncological variables included: age, BMI, active smoking status, diabetes, postmastectomy radiation therapy, history of radiation therapy and chemotherapy. Surgical variables included operative time, intraoperative tissue expander fill volume and final implant fill volume. Complications and final reconstruction technique (continued prosthetic or conversion to autologous) were tracked via retrospective review of physician and clinical notes.

Four blinded members of the division of plastic surgery who did not participate in the care of the patients were asked to independently rate postoperative anterior photographs of patients' breasts using a threepoint scale (0 to 2 ) with respect to five distinct aesthetic domains: breast mound volume, contour, placement, scarring and inframammary fold. Additional photographic views were inconsistently captured for patients and, therefore, not incorporated into the analysis. Gui et al (17) described a rating of zero in each of the respective fields as the following: marked difference in volume relative to the contralateral side; marked contour deformity or shape asymmetry; marked displacement of breast mound; hypertrophic scars and evident contracture; and a poorly defined inframammary fold. A score of 1 on the Lowery scale reflected mild discrepancies in volume and contour relative to the contralateral side, fair scarring (ie, poor colour match or wide scars without hypertrophy or contracture) and a defined yet asymmetrical inframammary fold. Any criterion with a score of 2 had quality aesthetic outcomes - specifically, minimal differences in volume, contour

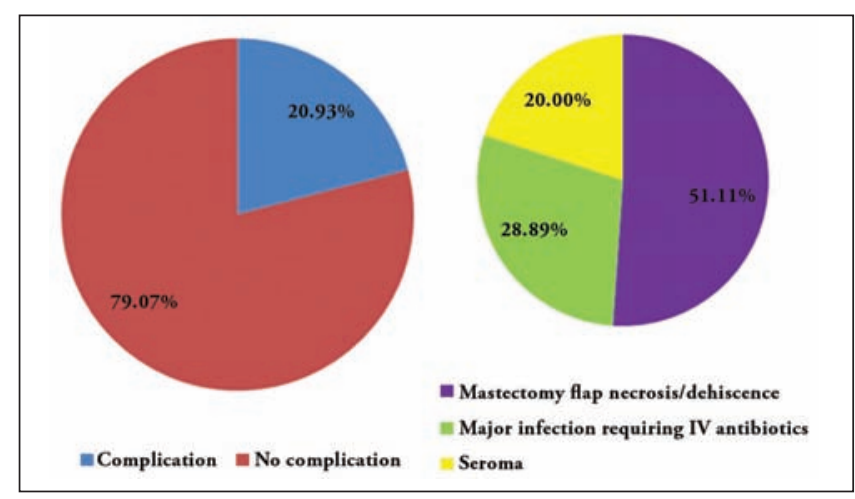

Figure 1) Breakdown of complications in the patient population. IV Intravenous

and placement, thin scars and symmetrical inframammary folds. Kappa $(\kappa)$ scores were calculated to statistically evaluate the inter-rater agreement of the four raters in the study; all measures fell into the good or excellent categories $(\kappa>0.60)$.

Aesthetic scores of the cohorts with and without complications were statistically compared and analyzed using Student's $t$ tests. Demographic variables were compared using Student's $t$ tests for continuous variables and $\chi^{2}$ or Fisher's exact test for categorical variables, as appropriate. A complication was defined as the presence of one or more of the following: mastectomy flap necrosis or dehiscence, seroma and infection requiring intravenous (IV) antibiotics (ie, National Cancer Institute Common Toxicity Criteria grade 3 or higher) (27). The complication cohort was further stratified according to final reconstruction method (implant versus autologous reconstruction), with aesthetic scores evaluated using Student's $t$ tests. All analyses were performed using SPSS version 20.0 (IBM Corporation, USA).

\section{RESULTS}

Of the 172 patients who met the inclusion criteria, 36 (20.93\%) experienced at least one defined complication (Table 1). The most common complication was mastectomy flap necrosis/dehiscence, found in $63.89 \%$ of patients with a recorded complication. Slightly more than $35 \%$ of these patients also experienced a major infection requiring IV antibiotics and $25 \%$ had a seroma (Figure 1 ). The cohort with complications had, on average, a higher BMI $\left(29.40 \mathrm{~kg} / \mathrm{m}^{2}\right.$ versus $\left.27.04 \mathrm{~kg} / \mathrm{m}^{2} ; \mathrm{P}=0.038\right)$ compared with the population without complications (Table 1). However, the cohorts were relatively similar regarding other captured characteristics, with no significant differences in age, active smoking status, chemotherapy, diabetes and hypertension.

Eighteen of the 36 patients who experienced a complication salvaged their expander and continued with prosthetic reconstruction, while the remaining 18 converted to autologous reconstruction. The aesthetic scores for all five domains (breast mound volume, contour, placement, scarring and the inframammary fold) for patients with a complication who kept their expander and those without any complication are presented in Figure 2. Inter-rater agreement on aesthetic scoring was examined by kappa score analysis and deemed to be acceptable $(\kappa>0.60)$. The inframammary fold proved to be the highest-scoring category in the complication cohorts, while placement was the highest scoring in the group without complication. The lowest-scoring category for patients who completed prosthetic reconstruction (with or without complications) was breast contour. The population without complications trended toward higher aesthetic scores compared with the population who experienced a complication and retained the expander for all five domains (breast mound volume, contour, placement, scarring and inframammary fold definition); however, these did not reach statistical significance. Photographic documentation of aesthetic outcomes in patients who experienced complications is presented in Figures 3 and 4. 


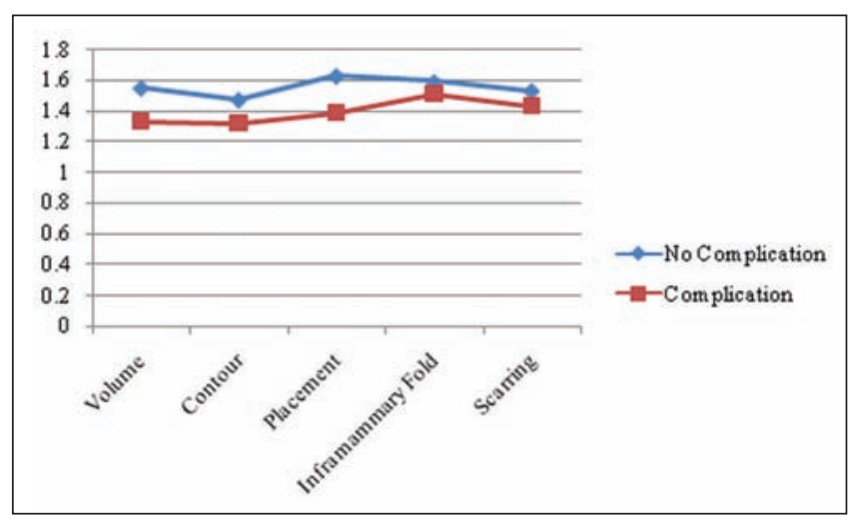

Figure 2) Aesthetic scores in patients who experienced a complication and completed prosthetic reconstruction compared with patients without complications
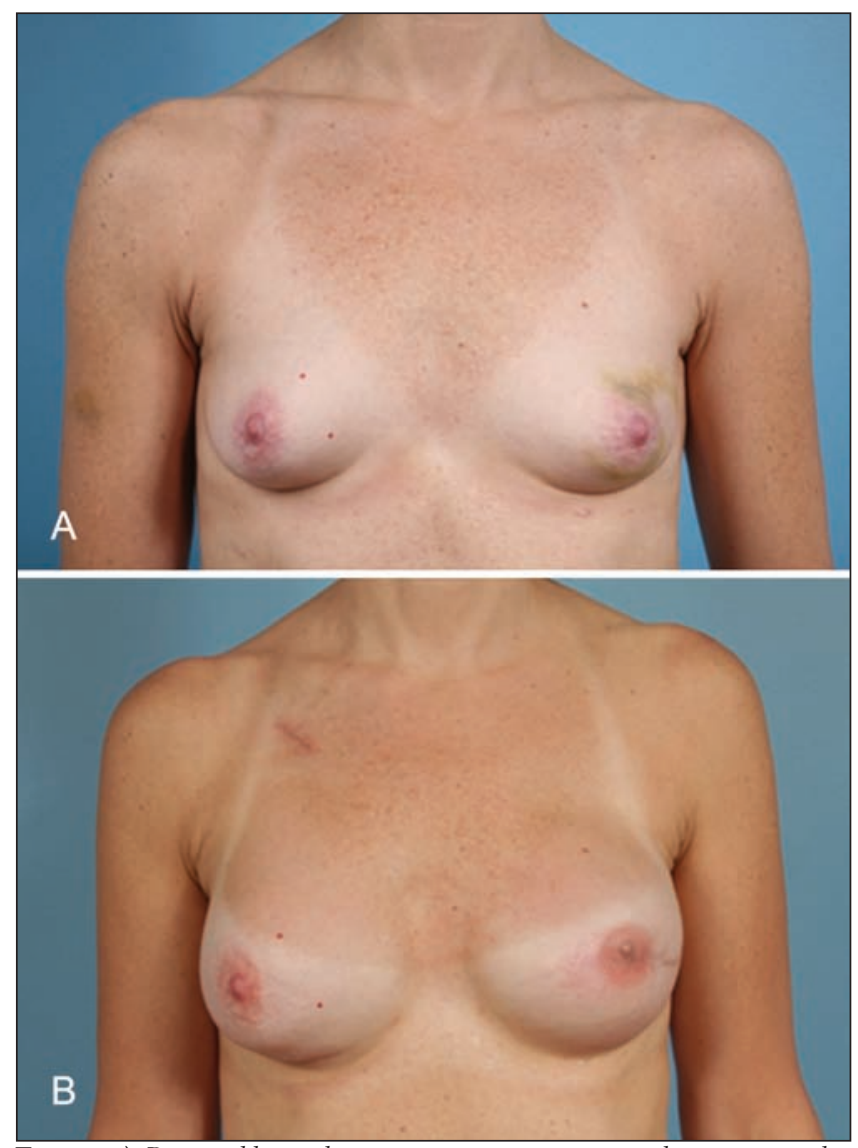

Figure 3) Reasonable aesthetic outcomes in a patient who experienced a complication. A Preoperative photograph. B Postoperative photograph. This is a 53-year-old woman who underwent left skin-sparing mastectomy with CPX3 expander placement, followed by postoperative radiation. She acquired a major infection requiring hospital admission and intravenous antibiotics. She subsequently underwent exchange to silicone implant with contralateral augmentation for symmetry. Figure $2 \mathrm{~B}$ represents her photographic result eight months after resolution of the infection

Aesthetic scores for all five domains were also compared within the population that experienced a complication. Evaluation based on final reconstruction revealed that patients who converted to an autologous tissue flap had superior aesthetic ratings in breast volume, contour and placement, as well as inframammary fold definition, compared with those who completed implant surgery (Figure 5).
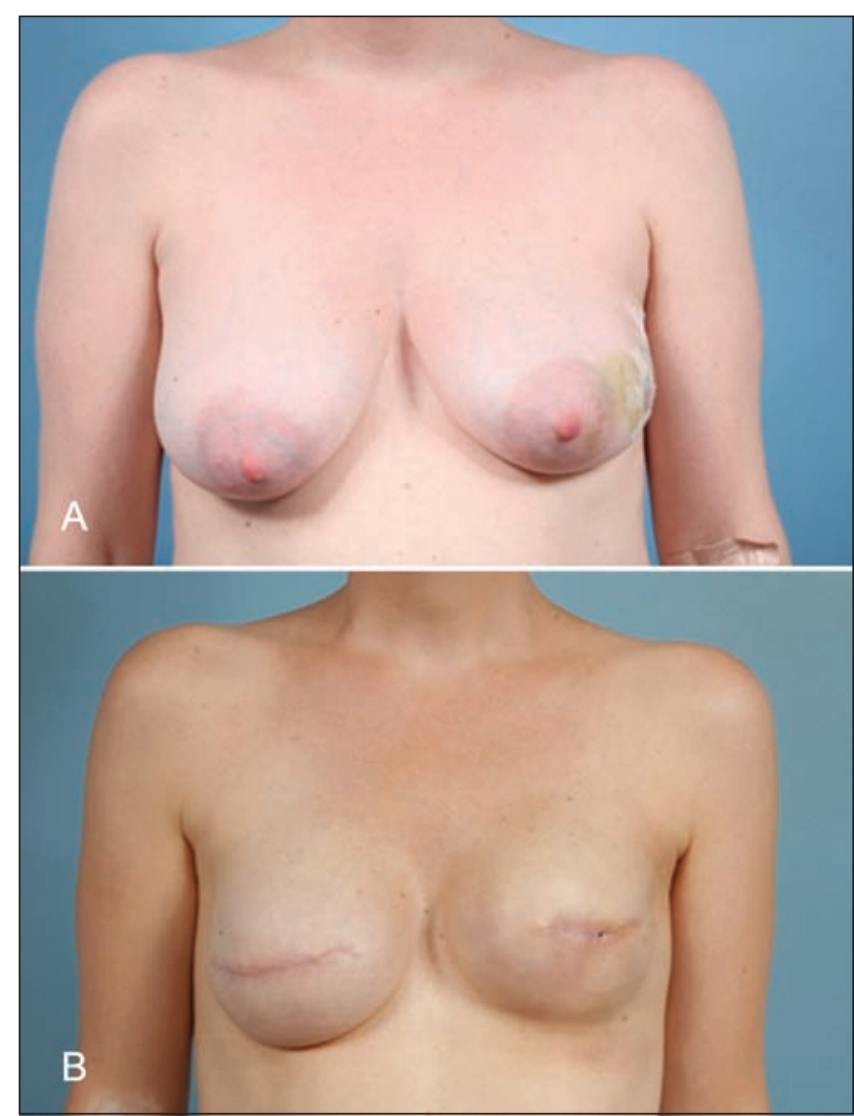

Figure 4) Poor aesthetic outcomes in a patient who expereinced a complication. A Preoperative photograph. B Postoperative photograph. This is a 34-year-old woman who underwent bilateral skin-sparing mastectomy with expander placement, followed by postoperative radiation to the left breast. She experienced left mastectomy flap necrosis requiring debridement. The flap was salvaged without surgery and she subsequently underwent bilateral exchange to silicone implants. Note the postoperative tightening, apparent volume loss and elevation of the inframammary fold nine months after resolution of her complication

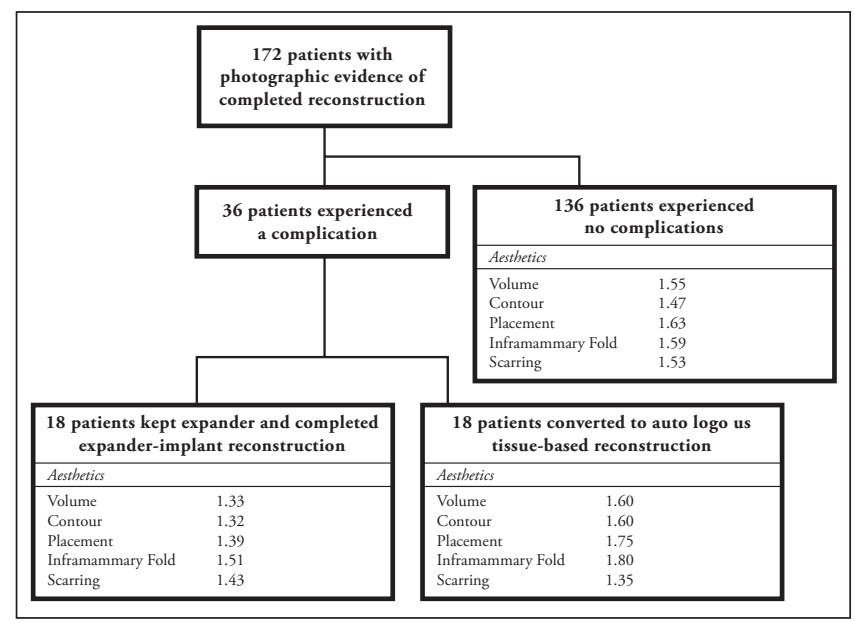

Figure 5) Tracking aesthetic outcomes in implant-based reconstruction with complications

\section{DISCUSSION}

The literature has shown that breast reconstruction helps ameliorate the known physical, emotional and psychological impact of mastectomy in breast cancer patients (1-5). The aesthetic outcomes of reconstruction, in particular, serve as an important contributor to the 
recovery and overall quality of life in this patient population. As such, concern exists as to how - and to what degree - complications following reconstructive surgery impact final aesthetic outcomes and patient satisfaction. While many hypothesize that postoperative complications do impact cosmesis, there remains a paucity of firm data to support this putative connection.

Many studies have focused on aesthetic results and patient satisfaction following breast reconstruction, and additional investigation has been conducted on factors that influence final cosmesis $(6,18,28,29)$. However, the impact of such findings is mitigated by the fact that the majority of these studies used nonvalidated aesthetic scoring scales and lacked details regarding specific aesthetic domains. While one specific study revealed that implant patients with complications have lower aesthetic satisfaction rates compared with those who did not experience a complication, the authors did not provide adequate information regarding the final reconstruction course of these cases; these findings also lacked any correlation to specific aesthetic domains or aesthetic scores. Therefore, our understanding of how complications directly impact breast reconstruction aesthetics remains limited. The present study was the first to track and quantitatively evaluate aesthetic outcomes of implant reconstructions that have had complications using a validated aesthetic scoring scale.

Patients who experienced a complication in our study were relatively similar to those who did not experience a complication, with the exception of having a significantly higher average BMI. Aesthetic analysis revealed no significant differences in scores between the populations with and without complications in any of the five measured aesthetic domains. While the complication cohort did trend toward lower average scores in all domains, this may be partially attributable to predisposing patient factors. Importantly, the higher BMI and greater use of radiation noted in this population were likely partial contributors to poorer aesthetic scores. This is substantiated by examination of radiation use and outcomes in our own database, which revealed that average contour and placement scores were 1.33 and 1.45 in the radiated cohort, respectively, compared with scores of 1.51 and 1.74 in the nonradiated cohort $(\mathrm{P}<0.05)$.

The ability to obtain aesthetic results following a complication that were not statistically different from results in those without complications may reflect the surgeon's refined attempt to salvage the initial implant reconstruction. In other circumstances, the improved cosmesis was achieved through conversion to an autologous tissuebased method. Of note, patients who had a complication and retained their original expander displayed a downward trend in aesthetic scores for all five domains compared with the uncomplicated population. Those who experienced a complication and decided to convert to autologous reconstruction actually obtained higher aesthetic scores than patients who never experienced a complication. This is consistent with previous literature reporting that autologous reconstruction yields the best aesthetic results $(6,18)$. While a postoperative complication is never a desired or intended outcome, our results provide information that may aid in patient education both preoperatively and in the postoperative period. Specifically, for individuals who encounter a complication, it may be helpful to understand the benefits and drawbacks of trying to salvage an original reconstruction compared with converting to autologous reconstruction.

We acknowledge that the insignificant variances in aesthetic values between patients with complications may correlate to significant clinical differences for patients. A study by Colakoglu et al (22) revealed a significant decrease in postreconstruction aesthetic satisfaction in individuals who experienced a complication. However, it is unknown what impact the complications specifically had on cosmesis because details regarding aesthetics were not reported. Moreover, participant demographic data were not provided and, therefore, certain patient factors - including radiation use - could have contributed to poorer aesthetic outcomes in these patients. Additionally, the survey used in the study by Colakoglu et al (22) may have been subject to participant bias because individuals who experienced a complication could have held a more negative impression of their overall postoperative experience and been inclined to provide lower satisfaction scores for any area pertaining to their operation. Additional analysis regarding the association between complications and aesthetic satisfaction and scores is, therefore, needed to allow for further clarification of this relationship.

We recognize that our study had inherent limitations. Implementing a minimum follow-up period of 130 days reduced the number of patients included. Our study population size was also limited by a lack of proper photographic documentation in many tracked patients. Even with a set follow-up period in place, we acknowledge the possibility that unresolved complications could have been present at the time of aesthetic evaluation. This may have contributed to the lower, albeit insignificant, aesthetic scores associated with the complication cohort in the present study. While others place merit in computer-assisted volumetric evaluations of photographs, scoring scales present several advantages, namely accessibility, intuitively meaningful data and lower costs. Therefore, we used a validated scale specific to breast cosmesis evaluation with well-described subcriteria. The specific scale used in the present study has significantly higher inter-rater reliability compared with scales without specific criteria. To prove this, we calculated kappa scores to statistically evaluate the inter-rater agreement of the four raters in our study and all measures fell into the good or excellent categories $(\kappa>0.60)$.

\section{CONCLUSION}

Through the present quantitative aesthetic assessment of prosthetic breast reconstruction cases with complications, we reveal that both continuance of prosthetic reconstruction and conversion to autologous reconstruction serve as viable options to obtain adequate aesthetic scores. Specifically, patients with salvaged expanders did not experience a significant adverse impact to breast placement, contour and volume, scarring or inframammary fold definition scores. By isolating specific features of aesthetic outcomes, these findings will enhance the management of patient expectations.

\section{REFERENCES}

1. Schain WS. Breast reconstruction: Update of psychosocial and pragmatic concerns. Cancer 1991;68:1170.

2. Rowlan JH, Holland JC, Chaglassian T, Kinne D. Psychological response to breast reconstruction: Expectations for and impact on postmastectomy functioning. Psychosomatics 1993;34:241.

3. Teimourian B, Adham MN. Survey of patient's responses to breast reconstruction. Ann Plast Surg 1982;9;321.

4. Wilkins EG, Cederna PS, Lowery JC, et. al. Prospective analysis of psychosocial outcomes in breast reconstruction: One-year postoperative results from the Michigan Breast Reconstruction Outcome Study. Plast Reconstr Surg 2000;106:1014-25.

5. Beesley H, Ullmer H, Holcombe C, Salmon P. How patients evaluate breast reconstruction after mastectomy, and why their evaluation often differs from that of their clinicians.

J Plast Reconstr Aesthet Surg 2012;65:1064-71.

6. Kroll SS, Baldwin B. A comparison of outcomes using three different methods of breast reconstruction. Plas Reconstr Surg 1992;90:455.

7. Alderman AK, Wilkins EG, Kim HM, Lowery JC. Complications in postmastectomy breast reconstruction: Two-year results of the Michigan Breast Reconstruction Outcome Study. Plast Reconstr Surg 2002;109:2265.

8. McCarthy CM, Mehrara, BJ, Riedel E, et al. Predicting complications following expander/implant breast reconstruction: An outcomes analysis based on preoperative clinical risk. Plast Reconstr Surg 2008;121:1886-92.

9. Buck DW II, Shenaq D, Heyer K, Kato C, Kim JY. Patientsubjective cosmetic outcomes following the varying stages of tissue expander breast reconstruction: The importance of completion. Breast 2010;19:521-6.

10. Cordeiro PG, McCarthy CM. A single surgeon's 12-year experience with tissue expander/implant breast reconstruction: Part II. An analysis of long-term complications, aesthetic outcomes, and patient satisfaction. Plast Reconstr Surg 2006;118:832-9. 
11. Cordeiro PG, Pusic AL, Disa JJ, McCormick B, VanZee K. Irradiation after immediate tissue expander/implant breast reconstruction: Outcomes, complications, aesthetic results, and satisfaction among 156 patients. Plast Reconstr Surg 2004;113:877-81

12. Roostaeian J, Sanchez I, Vardanian A, et al. Comparison of immediate implant placement versus the staged tissue expander technique in breast reconstruction. Plast Reconstr Surg 2012;129:909e-918e

13. Ramon Y, Ullmann Y, Moscona R, et al. Aesthetic results and patient satisfaction with immediate breast reconstruction using tissue expansion: A follow-up study. Plast Reconstr Surg 1997;99:686-91.

14. Clough KB, O’Donoghue JM, Fitoussi AD, Nos C, Falcou MC. Prospective evaluation of late cosmetic results following breast reconstruction: I. Implant reconstruction. Plast Reconstr Surg 2001;107:1702-9.

15. Castello JR, Garro L, Najera A, Mirelis E, Sanchez-Olaso A, Barros J. Immediate breast reconstruction in two stages using anatomical tissue expansion. Scand J Plast Reconstr Surg Hand Surg 2000;34:167-71.

16. Krueger EA, Wilkins EG, Strawderman M, et al. Complications and patient satisfaction following expander/implant breast reconstruction with and without radiotherapy. Int J Radiat Oncol Biol Phys 2001;49:713-21.

17. Gui GP, Tan SM, Faliakou EC, Choy C, A'Hern R, Ward A. Immediate breast reconstruction using biodimensional anatomical permanent expander implants: A prospective analysis of outcome and patient satisfaction. Plast Reconstr Surg 2003;111:125-38.

18. Rosen PB, Jabs AD, Kister SJ, Hugo NE. Clinical experience with immediate breast reconstruction using tissue expansion or transverse rectus abdominis musculocutaneous flaps. Ann Plast Surg $1990 ; 25: 249-51$.

19. Yueh JH, Slavin SA, Adesiyun T, et al. Patient satisfaction in postmastectomy breast reconstruction: A comparative evaluation of DIEP, TRAM, latissimus flap, and implant techniques.

Plast Reconstr Surg 2010;125:1585-95.
20. Padubidri AN, Yetman R, Browne E, et al. Complications of postmastectomy breast reconstruction in smokers, exsmokers, and nonsmokers. Plast Reconstr Surg 2001;107:350-1.

21. Lin KY, Johns FR, Gibson J, Long M, Drake DB, Moore MM. An outcome study of breast reconstruction: Presurgical identification of risk factors for complications. Ann Surg Oncol 2001;8:586-91.

22. Colakoglu S, Khansa I, Curtis MS, et al. Impact of complications on patient satisfaction in breast reconstruction. Plast Reconstr Surg 2011;127:1428-36.

23. Khan NA, Quan H, Bugar JM, Lemaire JB, Brant R, Ghali WA. Association of postoperative complications with hospital costs and length of stay in a tertiary care center. J Gen Intern Med 2006;21:177-80.

24. Fleischmann KE, Goldman L, Young B, Lee TH. Association between cardiac and noncardiac complications in patients undergoing noncardiac surgery: Outcomes and effects on length of stay. Am J Med 2003;115:515-20.

25. Dimick JB, Chen SL, Taheri PA, Henderson WG, Khuri SF, Campbell DA Jr. Hospital costs associated with surgical complications: A report from the private-sector National Surgical Quality Improvement Program. J Am Coll Surg 2004;199:531-7.

26. Kalish RL, Daley J, Duncan CC, Davis RB, Coffman GA, Iezzoni LI Costs of potential complications of care for major surgery patients. Am J Med Quality 1995;10:48-54.

27. National Cancer Institute. Common Toxicity Criteria. $<$ http://ctep.cancer.gov/protocolDevelopment/electronic applications/ctc.htm> (Accessed January 17, 2013).

28. Dutra AK, Neto MS, Garcia EB, et al. Patients' satisfaction with immediate breast reconstruction with a latissimus dorsi musculocutaneous flap. J Plast Surg Hand Surg 2012;46:349-53.

29. Eriksen C, Lindgren EN, Frisell J, Stark B. A prospective randomized study comparing two different expander approaches in implant-based breast reconstruction: One stage versus two stages. Plast Reconstr Surg 2012;130:254e-264e. 